\title{
Significance of Dok2 Protein in Cancer Prognosis and Progression
}

\section{Deshpande RP* and Phanithi PB*}

Department of Biotechnology and Bioinformatics, School of Life Sciences, University of Hyderabad, Telangana State, India

\begin{abstract}
Cancer is the most leading cause of deaths worldwide. Despite present understanding and experimental advancements, the morbidity and mortality still remain high. Dok2 have been visualized as a key player in multiple biological processes as inflammation, differentiation, cellular migration and even as an important marker for tumor progression. Recent reports have vividly discussed the regulatory aspects and prognostic aspects of Dok2. Here, we sought to summarize the recent shreds of evidence of Dok2 involvement in carcinogenesis. Dok2 represents an attractive marker for cancer progression and represents a valuable therapeutic target.
\end{abstract}

Keywords: Dok2; Cancer; Progression; Klf2; EGFR

\section{Introduction}

\section{Search strategy}

We executed systematic search using search engines as PubMed, Scholar Google for research articles of Dok2 in association with cancer. The search was limited to study revealing basic functions in light of its molecular mechanisms of action. References of published articles were seen for eligible details.

\section{Study selection}

The study selection included articles elaborating detailed mechanism of action and articles which are in relevance to cancer progression. We found very few articles elaborating detailed downstream targets. Papers were read carefully to know the experimental validation for downstream signaling proteins as well as its prognostic efficacy.

\section{Data extraction}

The search included papers with basic and experimental details in reverence to carcinogenesis. The cross references was screened for more clarity and basic details. The details included cancer type, prognosis details and experimental evidences for downstream targets.

\section{Biology of Dok2}

Downstream of tyrosine kinase (Dok2) belongs to a family of adapter protein reported to be responsive for the protein tyrosine kinase signaling. Dok family of proteins is known to localize on chromosome no 8. Members of Dok family of protein have three domains: A N terminal homology domain, a phospho tyrosine bonding domain and a $\mathrm{C}$ terminal proline rich domain with few tyrosine residues. This C- terminal with $\mathrm{SH} 2$ and $\mathrm{SH} 3$ domain recruits the signaling intermediates on growth factor stimulation [1-4]. Epidermal growth factor receptor signaling is essentially been viewed as an Important player in shaping cancer microenvironment [4] and an important target for cancer therapy [5]. Dok1-3 are reported to modulate epidermal growth factor receptor [6,7] as well as platelet derived growth factor receptor and associated signaling pathways $[1,8,9]$. Knock out mutants with Dok-1/Dok-2 have been reported to be associated with leukemia genesis $[10,11]$. Dok1 and Dok2 are related with an array of signaling pathways including TLR4 [12], CD200R pathway [13] and by signaling lymphocyte activation molecule (SLAM) [14]. Dok1 and Dok2 have been preferentially known to be expressed on immune cells but predicted to have non-immunological functions as well on account of its expression on cells of non-hematopoietic lineage [13,14]. Studies have shown that Dok1 and Dok2 plays an important role in TLR2 based signaling in astrocytes and microglia. This study also shows that activation of Dok1 and Dok2 results in cytokine production mediated by RasGAP dependent ERK and NF- $\kappa$ B activation. Dok1 and Dok2 are shown as novel targets for neuroinflammatory conditions [15]. In addition, Dok2 proteins has been connected with multiple biological processes including differentiation [16], cellular motility [17,18]. It has been reported that constitutive expression of Dok2 negatively regulates T cell development through interaction with RasGAP and Nck [19].

\section{Dok2 and cancer}

Dok2 expression has been reported to be associated with EGFR expression in lung adenocarcinoma. Here, it has been shown that EGFR mutations are coupled with genomic loss of Dok2. This loss of Dok2 in genetically engineered mouse cooperates with EGFR to promote tumorigenesis [20]. In gastric cancer studies, Dok2 has been reported to express in normal gastric mucosa while difference in expression pattern was observed in gastric cancer cell lines. Further, these studies notes that Dok 2 could be a useful marker to predict prognosis after curative resection [21]. Another study points that Dok 2 was lost in $42 \%$ of gastric cancer cases. However, the concomitant molecular mechanisms in gastric cancer are still remains at large [22]. In colorectal cancer studies, Dok 2 has been reported to express in $66.7 \%$ of gastric cancer samples. It is further predicted as marker for poor prognosis [23]. Another independent study shows that Dok2 was lost on $36 \%$ of colorectal cancer [22]. However, the mechanisms behind these alterations are not known yet. Chronic myelomonocytic leukemia (CMML) studies show that a mutation (L238P) in Dok2 is unable to inhibit ERK activation [24]. Studies in mouse erythroleukemia cells shows that Dok2 regulates the expression of Klf1 by binding to its promoter region and have a role in erythropoiesis. This study also shows that Dok2 is localized in cytoplasm and nucleus [25]. Epigenetic analysis of 45 ovarian cancer samples reveals that Dok2 underwent extensive methylation and its

*Corresponding author: Dr. Ravindra Pramod Deshpande and Prakash Babu Phanithi, Department of Biotechnology and Bioinformatics, School of Life Sciences University of Hyderabad, Telangana State, India Tel: 040-23134584, Fax: 04023010120; E-mail: prakash@uohyd.ac.in or ravi.deshpande3@gmail.com

Received November 15, 2017; Accepted November 28, 2017; Published December 01, 2017

Citation: Deshpande RP, Phanithi PB (2017) Significance of Dok2 Protein in Cancer Prognosis and Progression. J Mol Genet Med 11: 310 doi:10.4172/17470862.1000310

Copyright: ( 2017 Deshpande RP, et al. This is an open-access article distributed under the terms of the Creative Commons Attribution License, which permits unrestricted use, distribution, and reproduction in any medium, provided the original author and source are credited 


\begin{tabular}{|c|c|c|c|}
\hline Gene & Cancer & Target genes & References \\
\hline \multirow{4}{*}{ Dok2 } & Lung adenocarcinoma & Ras & {$[20]$} \\
\cline { 2 - 4 } & Gastric cancer & -- & {$[21,24]$} \\
\cline { 2 - 4 } & Colorectal cancer & -- & {$[23,22]$} \\
\cline { 2 - 4 } & $\begin{array}{c}\text { chronic myelomonocytic } \\
\text { leukemia (CMML) }\end{array}$ & ERK & {$[24]$} \\
\cline { 2 - 4 } & Erythroleukemia & Klf1 & {$[25]$} \\
\cline { 2 - 4 } & Ovarian cancer & -- & {$[26]$} \\
\cline { 2 - 4 } & Astrocytoma & -- & {$[27]$} \\
\hline
\end{tabular}

Table 1: Association of Dok2 expression in cancer.

repression was found to increase carboplatin resistance by hampering apoptosis and anoikis $[26,27]$.

\section{Discussion}

We have reported that Dok2 protein and RNA are overexpressed in low and high grade of astrocytoma tissue samples and its overexpression was correlated to poor prognosis. Real time PCR and western blotting results were supported by immunohistochemistry analysis. We further show that Dok2 expression was region specific with dominance of frontal and temporal lobes [23]. We also report that Dok2 is expressed in U87 malignant glioma cell lines and nitidine chloride can be the candidate drug targeting its expression [28]. The details of Dok2 reports with reported target genes have been presented in Table 1 .

\section{Concluding Remarks}

Dok2 may be viewed as an attractive marker for cancer progression. Its reported therapeutic value warrants further investigations.

\section{Conflict of Interest}

None

\section{Ethical Approval and Informed Consent}

Not applicable.

\section{Funding}

Authors thank financial assistance from Department of Science and technology (DST- India) (Grant no: SB/EMEQ-257/2013, SR/CSRI/196/2016), Department of Biotechnology (DBT-India) (Grant No. BT/PR18168/MED/29/1064/2016, BT/ PR13111/MED/29/149/2009) and University with potential for excellence (UPEIndia) (Grant no: UH/UGC/UPE-2/Interface studies/ Research Projects/B1.4, UH/ UPE-2/28/2015) for lab funding. RDP thankful to Department of Biotechnology (DBT-India) (Award no: DBT JRF/2011-12/95) for student fellowship.

\section{References}

1. Zhao M, Janas JA, Niki M, Pandolfi PP, Van Aelst L (2006) Dok-1 independently attenuates Ras/mitogen-activated protein kinase and SRC/C-MYC pathways to inhibit platelet-derived growth factor-induced mitogenesis. Mol Cell Biol 26: 2479-2489.

2. Songyang Z, Yamanashi Y, Liu D, Baltimore D (2001) Domain-dependent function of the rasGAP-binding protein p62(Dok) in cell signaling. J Biol Chem 276: $2459-2465$.

3. Zhao M, Schmitz AA, Qin Y, Di Cristofano A, Pandolfi PP, et al. (2001) Phosphoinositide 3-kinase-dependent membrane recruitment of p62(Dok) is essential for its negative effect on mitogen-activated protein (MAP) kinase activation. J Exp Med 194: 265-74.

4. Sasaki T, Hiroki K, Yamashita Y (2013) The role of epidermal growth factor receptor in cancer metastasis and microenvironment. BioMed Res Int 3: 1-4.

5. Seshacharyulu P, Ponnusamy MP, Haridas D, Jain M, Ganti AK, et al. (2012) Targeting the EGFR signaling pathway in cancer therapy. Expert opinion on therapeutic targets. 16: 15-31.

6. Van Slyke P, Coll ML, Master Z, Kim H, Filmus J, et al. (2005) Dok-R mediates attenuation of epidermal growth factor-dependent mitogen-activated protein kinase and AKT activation through processive recruitment of C-SRC and CSK.
Mol Cell Biol 25: 3831-3841.

7. Zhang Y, Yan Z, Farooq A, Liu X, Lu C, et al. (2004) Molecular basis of distinct interactions between Dok1 PTB domain and tyrosine-phosphorylated EGF receptor. J Mol Biol 343: 1147-1155.

8. Carpino N, Wisniewski D, Strife A, Marshak D, Kobayashi R, et al. (1997) p62(Dok): A constitutively tyrosine-phosphorylated, GAP-associated protein in chronic myelogenous leukemia progenitor cells. Cell 88:197-204.

9. Jones N, Dumont DJ (1999) Recruitment of Dok-R to the EGF receptor through its PTB domain is required for attenuation of ERK MAP kinase activation. Curr Biol 9: 1057-1060.

10. Niki M, Di Cristofano A, Zhao M, Honda H, Hirai H, et al. (2004) Role of Dok-1 and Dok-2 in leukemia suppression. J Exp Med 200: 1689-1695.

11. Yasuda T, Shirakata M, Iwama A, Ishii A, Ebihara Y, et al. (2004) Role of Dok-1 and Dok-2 in myeloid homeostasis and suppression of leukemia. J Exp Med 200: 1681-1687.

12. Shinohara H, Inoue A, Toyama-Sorimachi N, Nagai Y, Yasuda T, et al. (2005) Dok-1 and Dok-2 are negative regulators of lipopolysaccharide-induced signaling. J Exp Med 201: 333-339.

13. Berger AH, Niki M, Morotti A, Taylor BS, Socci ND, et al. (2010) Identification of Dok genes as lung tumor suppressors. Nature genet 42: 216-223.

14. 14. Latour S, Gish G, Helgason CD, Humphries RK, Pawson T, et al. (2001) Regulation of SLAM-mediated signal transduction by SAP, the X-linked lymphoproliferative gene product. Nature Immun 2: 681-690.

15. Downer EJ, Johnston DG, Lynch MA (2013) Differential role of Dok1 and Dok2 in TLR2-induced inflammatory signaling in glia. Molecular and cellular neurosciences. 56: 148-158.

16. Grimm J, Sachs M, Britsch S, Di Cesare S, Schwarz-Romond T, et al. (2001) Novel p62(Dok) family members, Dok-4 and Dok-5, are substrates of the c-Ret receptor tyrosine kinase and mediate neuronal differentiation. J Cell Biol 154 345-354.

17. Master Z, Jones N, Tran J, Jones J, Kerbel RS, et al. (2001) Dok-R plays a pivotal role in angiopoietin-1-dependent cell migration through recruitment and activation of Pak. Embo J 20: 5919-5928.

18. Hosooka T, Noguchi T, Nagai H, Horikawa T, Matozaki T, et al. (2001) Inhibition of the motility and growth of B16F10 mouse melanoma cells by dominant negative mutants of Dok-1. Mol Cell Biol 21: 5437-5446.

19. Gugasyan R, Quilici C, loa ST, Grail D, Verhagen AM, et al. (2002) Dok-related protein negatively regulates $T$ cell development via its RasGTPase-activating protein and Nck docking sites. J Cell Biol 158: 115-125.

20. Berger AH, Chen M, Morotti A, Janas JA, Niki M, et al. (2013) Dok2 inhibits EGFR-mutated lung adenocarcinoma. PloS one 8: 1-2.

21. Miyagaki H, Yamasaki M, Takahashi T, Kurokawa Y, Miyata H, et al. (2012) Dok2 as a marker of poor prognosis of patients with gastric adenocarcinoma after curative resection. Ann Surg Oncol 19: 1560-1567.

22. An CH, Kim MS, Yoo NJ, Lee SH (2011) Mutational and expressional analysis of a haploinsufficient tumor suppressor gene Dok2 in gastric and colorectal cancers. APMIS 119: 562-564.

23. Wen X, Zhou M, Guo Y, Zhu Y, Li H, et al. (2015) Expression and significance of Dok2 in colorectal cancer. Oncology letters 9: 241-244.

24. Coppin E, Gelsi-Boyer V, Morelli X, Cervera N, Murati A, et al. (2015) Mutational analysis of the Dok2 haploinsufficient tumor suppressor gene in chronic myelomonocytic leukemia (CMML). Leukemia 29: 500-502.

25. Tanaka Y, Kulkeaw K, Inoue T, Tan KS, Nakanishi Y, et al. (2014) Dok2 likely down-regulates KIf1 in mouse erythroleukemia cells. Anticancer Res 34: 45614567.

26. Lum E, Vigliotti M, Banerjee N, Cutter N, Wrzeszczynski KO, et al. (2013) Loss of Dok2 induces carboplatin resistance in ovarian cancer via suppression of apoptosis. Gynecologic Oncol 130: 369-376.

27. Deshpande RP, Sekhar CYB, Panigrahi M, Babu PP (2016) Region-specific Dok2 overexpression associates with poor prognosis in human astrocytoma. Molecular neurobiology 2: 1-3.

28. Deshpande RP, Babu PP (2017) Pdok2, caspase 3 dependent glioma cell growth arrest by nitidine chloride. Pharmacol Rep 1: 2 . 